\title{
Executive function network's white matter alterations relate to Parkinson's disease motor phenotype
}

Qinglu Yang,a,b, Shruti Nanivadekar, ${ }^{a, e}$, Paul A. Taylor ${ }^{\mathrm{c}}$, Zulin Dou ${ }^{\mathrm{b}}$, Codrin Lungu ${ }^{\mathrm{a}, \mathrm{f}}$, Silvina G. Horovitz ${ }^{\mathrm{a},}$

\section{Author Affiliations:}

${ }^{a}$ Human Motor Control Section, National Institute of Neurological Disorders and Stroke, National Institutes of Health, Bethesda, MD, United States

${ }^{b}$ The Third Affiliated Hospital of Sun Yat-sen University, Rehabilitation Department, Guangzhou, R. P. China

${ }^{c}$ Scientific and Statistical Computing Core, National Institutes of Health, Bethesda, MD, United States

\section{Present Address:}

${ }^{\mathrm{d}}$ The Eighth Affiliated Hospital of Sun Yat-sen University, Rehabilitation Department, Shenzhen, R.

P. China

e University of Pittsburgh School of Medicine, Pittsburgh, PA, United States

${ }^{\mathrm{f}}$ Division of Clinical Research, National Institute of Neurological Disorders and Stroke, National Institutes of Health, Rockville, MD, United States

\section{* Address for Correspondence:}

Silvina G. Horovitz, Ph.D.

Human Motor Control Section

National Institute of Neurological Disorders and Stroke

National Institutes of Health

Building 10 Room 7D-37 MSC1428, Bethesda, MD, 20892-1428, United States

E-mail: silvina.horovitz@,nih.gov

Telephone: +1 301-435-2163

Fax: +1 301-480-2286 
medRxiv preprint doi: https://doi.org/10.1101/2020.08.15.20174284; this version posted August 17, 2020. The copyright holder for this preprint (which was not certified by peer review) is the author/funder, who has granted medRxiv a license to display the preprint in It is made available under a CC-BY-NC-ND 4.0 International license.

\section{Abstract}

Parkinson's disease (PD) patients with postural instability and gait disorder phenotype (PIGD) are at high risk of cognitive deficits compared to those with tremor dominant phenotype (TD). Alterations of white matter (WM) integrity can occur in patients with normal cognitive functions (PD-N). However, the alterations of WM integrity related to cognitive functions in PD-N, especially in these two motor phenotypes, remain unclear. Diffusion tensor imaging (DTI) is a non-invasive neuroimaging method to evaluate WM properties and by applying DTI tractography, one can identify WM tracts connecting functional regions. Here, we 1) compared the executive function (EF) in PIGD phenotype with normal cognitive functions (PIGD-N) and TD phenotype with normal cognitive functions (TD-N) phenotypes; 2) used DTI tractography to evaluated differences in WM alterations between these two phenotypes within a task-based functional network; and 3) examined the WM integrity alterations related to EF in a whole brain network for PD-N patients regardless of phenotypes.

Thirty-four idiopathic PD-N patients were classified into two groups based on phenotypes: TD-N and PIGD-N, using an algorithm based on UPDRS part III. Neuropsychological tests were used to evaluate patients' EF, including the Trail making test part A and B, the Stroop color naming, the Stroop word naming, the Stroop color-word interference task, as well as the FAS verbal fluency task and the animal category fluency tasks. DTI measures were calculated among WM regions associated with the verbal fluency network defined from previous task fMRI studies, and compared between PIGD-N and TD-N groups. In addition, the relationship of DTI measures and verbal fluency scores were evaluated for our full cohort of PD-N patients within the whole brain network. These values were also correlated with the scores of the FAS verbal fluency task.

Only the FAS verbal fluency test showed significant group differences, having lower scores in PIGD-N when compared to TD-N phenotype $(p<0.05)$. Compared to the TD-N, PIGD-N group exhibited significantly higher MD and RD in the tracts connecting the left superior temporal gyrus and left insula, and those connecting the right pars opercularis and right insula. Moreover, compared to TD-N, PIGD-N group had significantly higher RD in the tracts connecting right pars opercularis and right pars triangularis, and the tracts connecting right inferior temporal gyrus and right middle temporal gyrus. For the entire PD-N cohort, FAS verbal fluency scores positively correlated with MD in the superior longitudinal fasciculus (SLF).

This study confirmed that PIGD-N phenotype has more deficits in verbal fluency task than TD-N phenotype. Additionally, our findings suggest: (1) PIGD-N shows more microstructural changes related to FAS verbal fluency task when compared to TD-N phenotype; (2) SLF plays an important role in FAS verbal fluency task in PD-N patients regardless of motor phenotypes. 
medRxiv preprint doi: https://doi.org/10.1101/2020.08.15.20174284; this version posted August 17, 2020. The copyright holder for this preprint (which was not certified by peer review) is the author/funder, who has granted medRxiv a license to display the preprint in It is made available under a CC-BY-NC-ND 4.0 International license.

Keywords: Parkinson's disease; motor phenotype; tremor; PIGD; normal cognitive functions; white matter; DTI

\section{Introduction}

Parkinson's disease (PD) is a major neurodegenerative disorder, with a central feature of neurodegeneration of dopaminergic neurons in the substantia nigra pars compacta [1,2]. The most common manifestations include the classic triad of motor symptoms of rest tremor, rigidity, and bradykinesia. PD patients can be classified into two groups with distinct motor phenotypes: 1) tremordominant (TD), and 2) being postural instability and gait difficulty (PIGD) [3,4]. Non-motor symptoms, such as olfactory and cognitive decline related to PD, can occur 5 to 10 years before motor symptoms onset $[5,6]$, suggesting that non-motor symptoms could be prodromal signs. Cognitive impairment, developing in some cases to dementia, is the most reported non-motor PD symptom affecting patients' quality of life [7].

Recent studies investigating the relationship between motor and cognitive symptoms in PD suggest that motor phenotype is an important influential factor affecting cognitive function [8,9]. The PIGD phenotype has been correlated with increased risk for dementia [8-11]. In a longitudinal study [8], TD phenotype with normal cognitive function (TD-N) at the first time point (yrs. of disease duration: mean $=9.5, \mathrm{SD}=5.6$ ) showed progression to dementia only after patients transitioned to PIGD. This transition was associated with accelerated cognitive decline and highly increased risk for subsequent dementia. PIGD phenotype, with normal cognitive functions (PIGD-N) at the first time point (yrs. of disease duration: mean=6.9, $\mathrm{SD}=4.7$ ), remained within their phenotype and had a significant higher odds ratio for dementia compared to those in TD. Another study following nondemented PD patients for 2 years showed similar results [11]. These reports suggest cognitive impairment pathology may share neuro-anatomical or neuro-chemical substrates with a specific motor phenotype, and encourage us to further explore the underpinnings of the cognitive decline in the different PD motor phenotypes.

It has been proposed that alterations in white matter (WM) integrity might influence cognitive functions in PD $[12,13]$. Deterioration of WM microstructure correlates with cognitive impairment in PD across different cognitive stages, from mild impairment to dementia [12]. Neuroimaging studies showed FA reductions in the superior longitudinal fasciculus (SLF) in the PIGD-N phenotype and increased MD in the motor circuits in the TD-N phenotype [14]. Further exploring these differences 
medRxiv preprint doi: https://doi.org/10.1101/2020.08.15.20174284; this version posted August 17, 2020. The copyright holder for this preprint (which was not certified by peer review) is the author/funder, who has granted medRxiv a license to display the preprint in

It is made available under a CC-BY-NC-ND 4.0 International license.

might unveil additional information about the mechanisms of how motor phenotypes relate to cognitive function in PD.

Diffusion tensor imaging (DTI) is a non-invasive imaging method to study the microstructure of WM integrity in vivo [15]. Three commonly used measurements of DTI are fractional anisotropy (FA), mean diffusivity (MD), and radial diffusivity (RD) [16]. Using probabilistic tractography, it is possible to estimate locations of WM bundles, and then to examine changes in diffusion parameters within each tract [17]. Such changes may help us to understand the pathological processes underlying diseases [18]. In addition, WM alterations have been observed before gray matter (GM) atrophy in PD [19], and has been suggested they might help assessing cognitive impairment early in the process of cognitive decline in PD.

In this study, we used DTI probabilistic tractography, as well as cognitive and clinical data from a cohort of PD-N to better understand: 1) the effects of motor phenotypes in executive function; 2) the effects of motor phenotypes in WM properties within a task-based executive functional network; and 3) the characteristics of WM alterations related to EF at a whole brain level in PD-N, regardless of motor phenotype.

\section{Patients and Methods}

\subsection{Subjects}

PD patients consented and evaluated at the National Institute of Health (NIH, Bethesda, MD, USA) between 2011 and 2015 for a deep brain stimulation protocol conducted under Institutional Review Board-approved guidelines, were included in this retrospective study. All subjects had a diagnosis of PD according to the United Kingdom Parkinson's Disease Society Brain Clinical Diagnosis Criteria [20,21]. The Mini Mental State Examination (MMSE) was used to define normal cognitive level [22]. The cutoff scores of MMSE were adjusted according to the educational level ( $>20$ for illiterates, $>$ 25 for individuals with 1 to 4 years of education, $>26$ for individuals with 5 to 8 years, $>28$ for individuals with 9 to 11 years, $>29$ for individuals with more than 11 years of education). The exclusion criteria were: 1) patients diagnosed with any neurological or psychiatric disease other than PD; 2) had global cognitive impairment (based on the Cognitive Impairment on Full Scale Intelligence Quotient (FSIQ) of WAIS-III Wechsler Adult Intelligence III, cut-off score less than 70); or 3) the use of illegal drugs. Cognitive function was evaluated in the clinically defined ON state by a certificated psychologist at the National Institute of Neurology and Stroke (NINDS, NIH, USA). All patients abstained from alcohol consumption for at least 24 hours before evaluations. 
medRxiv preprint doi: https://doi.org/10.1101/2020.08.15.20174284; this version posted August 17, 2020. The copyright holder for this preprint (which was not certified by peer review) is the author/funder, who has granted medRxiv a license to display the preprint in It is made available under a CC-BY-NC-ND 4.0 International license.

Physical and neurological evaluations were performed by NIH Parkinson's Disease Clinic neurologists. The Unified Parkinson's Disease Rating Scale part III (UPDRS-III) and the Hoehn and Yahr scale were used to each assess patient's motor function [23,24]. The UPDRS-III was performed in the morning, after 12 hours off any dopaminergic medication (clinically defined OFF state). After the evaluation, patients took their regular dose of dopaminergic medications. One hour later, patients were tested for the UPDRS-III in the clinically defined ON state.

The total dosage of antiparkinsonian medication was converted to Levodopa equivalent dose (LED) according to an established method [25]. Motor phenotypes were derived from the UPDRS-III in the OFF state based on Jankovic's classification system, as used in recent studies [4,26,27]. The tremor score was the sum of items 20 and 21, divided by 4. The PIGD score was the sum of items 22 to 27 and 31, divided by 15 . Phenotypes were categorized by the ratio of each patients' tremor score to his/her PIGD score. The TD-N group was defined as the ratio greater than or equal to 1.0. The PIGD-N group included all patients with a ratio less than or equal to 0.8. Subjects outside this range were excluded.

\subsection{Neuropsychological tests}

Neuropsychological tests were used to evaluate patients' EF, including the Trail making test part A and B, the Stroop color naming, the Stroop word naming, the Stroop color-word interference task, as well as the FAS verbal fluency task and the animal category fluency task of Delis-Kaplan Executive Function System (D-KEFS) [28,29]. All the neuropsychological tests were assessed in the clinical ON state.

\subsection{Image acquisition}

MRIs from all patients were collected in the clinical ON state using a 3.0 T MRI scanner (Philips Achieva XT, Philips Medical Systems, Best, the Netherlands). The acquisition protocol included T1weighted (T1w) turbo field echo, T2-weighted (T2w) turbo spin echo, and diffusion-weighted highangle echo-planar imaging (DWI) sequences as we previous reported [30]. The T1w sequence was acquired with the following parameters: $\mathrm{TR}=8.15 \mathrm{~ms}, \mathrm{TE}=3.735 \mathrm{~ms}$, slice thickness $=1.00 \mathrm{~mm}$, spacing between slices $=1.00 \mathrm{~mm}$, echo train length $=240, \mathrm{FOV}=240 \times 240 \mathrm{~mm}^{2}$, flip angle $=8^{\circ}$, acquisition matrix $=256 \times 256 \times 191$, and total acquisition time $=6 \min 53 \mathrm{~s}$. The T2 $\mathrm{w}$ sequence was collected with the following parameters: $\mathrm{TR}=2500 \mathrm{~ms}, \mathrm{TE}=235.648 \mathrm{~ms}$, slice thickness $=1.10 \mathrm{~mm}$, spacing between slices $=0.55 \mathrm{~mm}$, echo train length $=133, \mathrm{FOV}=250 \times 250 \mathrm{~mm}^{2}$, flip angle $=90^{\circ}$, acquisition matrix $=256 \times 256 \times 327$, and total acquisition time $=4 \min 37.5$ s. The DWI sequence 
medRxiv preprint doi: https://doi.org/10.1101/2020.08.15.20174284; this version posted August 17, 2020. The copyright holder for this preprint (which was not certified by peer review) is the author/funder, who has granted medRxiv a license to display the preprint in It is made available under a CC-BY-NC-ND 4.0 International license.

was collected with the following parameters: $\mathrm{TR}=9776.51 \mathrm{~ms}, \mathrm{TE}=65 \mathrm{~ms}$, slice thickness $=2 \mathrm{~mm}$, spacing between slices $=2 \mathrm{~mm}$, echo train length $=59, \mathrm{FOV}=224 \times 224 \mathrm{~mm}^{2}$ (in-plane resolution 2 $\times 2 \mathrm{~mm}^{2}$ ), flip angle $=90^{\circ}$, acquisition matrix $=112 \times 112 \times 78$, voxel size $=2 \mathrm{~mm}$ isotropic; 1 reference $b_{0}$ volume with no diffusion weighting $\left(\mathrm{b}=0 \mathrm{~s} / \mathrm{mm}^{2}\right)$ was collected, along with 33 noncollinear gradient directions with $b=1000 \mathrm{~s} / \mathrm{mm}^{2}$. DWI acquisition time was $6 \min 48 \mathrm{~s}$.

\subsection{Image processing}

\subsubsection{Pre-processing}

Image pre-processing was performed following our previously described method [30], utilizing the following software: Medical Image Processing, Analysis and Visualization (MIPAV) software package [31], TORTOISE (v. 3.1.2) [32], FreeSurfer (v. 5.0) [33], AFNI (v. 20.1.06) [34], SUMA [35] and FATCAT [36]. Briefly, anterior and posterior commissure (AC and PC) landmarks were manually defined on the mid-sagittal aligned T2w image using MIPAV. A rigid body transform was applied to $\mathrm{T} 2 \mathrm{w}$ resulting in a horizontal $\mathrm{AC}-\mathrm{PC}$ line and a vertical midsagittal plane. The re-aligned T2w images served as the co-registration target for the DWI volumes and the T1w volume.

The DWI volumes were first motion- and eddy-corrected (along with EPI distortion reduction), aligned to the target $\mathrm{T} 2 \mathrm{w}$ volume and resampled to $1.5 \mathrm{~mm}$ isotropic voxels using TORTOISE's 'DIFFPREP' program. The transformed volume was visually inspected. Uncertainty intervals of FA and principal diffusion directions were estimated with FATCAT's '3dDWUncert' using 500 jackknife resampling iterations, for subsequent use in probabilistic tractography, described below. The preprocessing script is included as Supplementary Material 1.

\subsubsection{ROIs definition and setup}

FAS verbal fluency network: Gray matter (GM) regions of interest (ROIs) from the CA_ML_18_MNIA atlas in AFNI [37] were selected based on previous FAS verbal fluency fMRI studies $[38,39]$ and include the bilateral prefrontal cortex pars triangularis and pars opercularis, inferior parietal lobule (IPL), inferior temporal gyrus (ITG), insula, middle temporal gyrus (MTG), superior parietal lobule (SPL), superior temporal gyrus (STG), thalamus, putamen, caudate, pallidum, and hippocampus (see Fig.1). Transformations were made using the AFNI's '3dQwarp' program [40]. Then, we nonlinearly mapped these ROIs to each subject diffusion space using AFNI's '3dNwarpApply' program, to be used as additional tractography targets within each subject's native space. We estimated this network to include in our analysis because the FAS verbal fluency network 
medRxiv preprint doi: https://doi.org/10.1101/2020.08.15.20174284; this version posted August 17, 2020. The copyright holder for this preprint (which was not certified by peer review) is the author/funder, who has granted medRxiv a license to display the preprint in

It is made available under a CC-BY-NC-ND 4.0 International license.

was the only EF task showing significant differences between the two phenotypes in our study (see section 3.1).

Whole brain network: In order to characterize the WM alterations related to EF at a whole brain level, regardless of motor phenotype, we used 83 GM ROIs from the Desikan-Killiany atlas of each subject's FreeSurfer parcellation [37]. Additionally, the ROIs from the Talairach-Tournoux atlas (TT_Daemon) were identified to specify deep nuclei ROIs including bilateral red nucleus, substantia nigra, subthalamic nucleus, and hypothalamus. These deep nuclei were chosen based on prior reports related to cognitive functions, freezing gait, and other effects in PD indicating WM alterations [4143]. The deep nuclei were added to GM ROIs by after transforming them to each individual's diffusion data by AFNI's '3dNwarpApply'. In total, 91 ROIs were included (detailed in Supplementary Material 2).

The procedures followed our previous reported method [30]. Briefly, the T1w volume was intensity-normalized using AFNI's '3dUnifize' and then skull stripped in FreeSurfer. The skull stripped T1w volume was registered to T2w volume using AFNI's 'align_epi_anat.py' with the local Pearson's coefficient (lpc) cost function [44]. The registered T1w was fed back into FreeSurfer for generating a cortical surface. Surface models and parcellation were created via another call to FreeSurfer's 'recon-all' command. The definition of two networks and the wrapping processes of the two networks to subject's space were described above. Each subject ROIs were inflated to the neighboring voxels surface and edges and stopped if it reached with another ROI (preventing ROI overlap) or voxels with an FA value larger than 0.2 (preventing WM overrun) using the FATCAT tool '3dROIMaker', resulting in the two networks used for ROI-based probabilistic tractography.
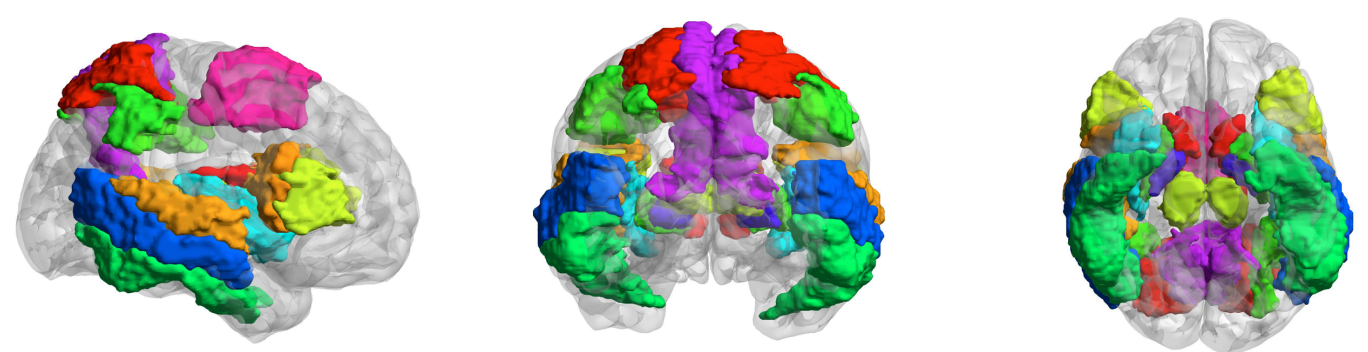

Fig. 1. Target areas for tractography. 26 ROIs included in the FAS verbal fluency task-based network. Regions displayed in MNI space.

\subsubsection{Probabilistic tractography}

Probabilistic tractography was used to estimate the WM tracts from each pair of ROIs for the whole brain analysis and within the FAS verbal fluency network described above. In FATCAT, the 
medRxiv preprint doi: https://doi.org/10.1101/2020.08.15.20174284; this version posted August 17, 2020. The copyright holder for this preprint (which was not certified by peer review) is the author/funder, who has granted medRxiv a license to display the preprint in It is made available under a CC-BY-NC-ND 4.0 International license.

probabilistic tractography analysis is based on the fiber assessment by continuous tracking including the diagonals (FACTID) algorithm, which has been shown to provide relatively robust results in both human and phantom testing studies [32]. We ran the program ' 3 dTrackID' in full probabilistic tracking mode (PROB), utilizing the tensor-uncertainty information described above, and the default tracking parameters (FA $>0.2$, turning angle $<60$, track length $>20 \mathrm{~mm}, 8$ seeds per voxel, thresholding fraction $>0.021$ ) with five seeds per voxel and a total of 5000 Monte Carlo iterations. Tracts passing through individual ROIs and locations of tracts that intersected any pair of ROIs were recorded. For each subject, an automatically generated '*.grid' file output of '3dTrackID' contained the statistical results describing the estimation of average DTI scalar parameters of interest (FA, MD, and RD) for WM ROIs connecting pairs of ROIs in the input GM network (91 x 91 for whole brain network, $26 \mathrm{x}$ 26 for FAS verbal fluency network) in matrix format.

\subsection{Statistics}

\subsubsection{Clinical and neuropsychological tests analysis}

AFNI's 3dMVM and the R statistics software (v.3.6.2, R Foundation for Statistical Computing, Vienna, Austria) were used for statistical analysis [45]. Normality assumptions were evaluated based on the residuals using the Shapiro-Wilk test. Clinic and neuropsychological tests between PIGD-N and TD-N phenotypes were analyzed using repeated measures ANCOVA with age, disease duration, and education level as covariates. The categorical variables were calculated by fisher test. UPDRS-III ON and OFF scores were compared by paired-sample two-tailed $t$-test $(p<0.05)$.

\subsubsection{Effects of PD motor phenotypes on WM alterations related to EF}

We analyzed WM differences between PIGD-N and TD-N phenotypes within the FAS verbal fluency network with an ANCOVA model, ran in AFNI's '3dMVM' program [45] (see Supplementary Material 3). Each subject's age, disease duration years, and FAS verbal fluency task scores were set as covariates. FA, MD, and RD were defined as response variables, and the effect of each assessed in a separate model. Testing was carried out in a hierarchical manner. First, "network level" significance was tested with the omnibus F-statistic for the main effects of phenotype on the FAS verbal fluency network, as well as for the interactions between phenotype with FAS verbal fluency scores, age, and years of duration. Second, when the F-statistic was significant, post-hoc follow-up t-tests were used within the same 3dMVM command to investigate and pinpoint the "ROI level" significance of which WM connections had the strongest relationship driving the network-level effect. In other words, the 
medRxiv preprint doi: https://doi.org/10.1101/2020.08.15.20174284; this version posted August 17, 2020. The copyright holder for this preprint (which was not certified by peer review) is the author/funder, who has granted medRxiv a license to display the preprint in It is made available under a CC-BY-NC-ND 4.0 International license.

network level F-statistic measured the primary effect of interest here, and when that showed a significant relation, then the ROI level post-hocs provided specific evidence about which parts of the network appeared to be driving the main effect (that is, which WM connections showed the strongest relationship, or whether the effect appeared to be relatively dispersed throughout the network). Due to the descriptive nature of the post-hoc tests, no multiple comparisons corrections were used. The omnibus F-test itself, a test of an intersection hypothesis, requires no multiple comparisons [46,47]

\subsubsection{Characteristics of WM alterations related to $E F$ in $P D-N$}

To estimate FAS verbal fluency scores effect on whole brain WM alterations, the ANCOVA model was separately used to estimate the FA, MD, and RD values in the whole brain network for the entire cohort (PD-N) regardless of phenotype (see Supplementary Material 3), following a similar strategy to the testing noted in the previous section for this whole brain network. In this part, we estimated the tractography at the whole brain level, as the FAS verbal fluency network is a part of the whole brain network. In the model, the FAS verbal fluency scores were defined as independent variables. DTI measurements were defined as separate response variables. FAS verbal fluency scores, age, and disease duration were included as covariates. The main effect of FAS scores was evaluated at the "network level" by omnibus F-statistics. When those showed significant relations, then post-hoc $t$ tests were performed to determine the most significant tracts "at the ROI level" between paired-ROIs contributing to the main effect.

\section{Results}

\subsection{Demographics and neuropsychological tests}

A total of 40 idiopathic PD subjects were recruited during the study period. Three subjects were excluded since they did not meet inclusion criterial (two had essential tremor and one had cervical dystonia). Another three subjects were excluded in the step of phenotype classifications. A total of 34 PD patients met all inclusion criteria and were included in the analysis. 19 patients were classified as TD-N and 15 as PIGD-N. The demographics and disease-related characteristics of included subjects are summarized in Table 1. EF scores of the entire PD cohort, and by the two phenotypes are described in Table 2. The FAS verbal fluency task showed significant difference between the two phenotype groups $\left(p<0.05, t_{(32)}=2.230\right)$. The TD-N group showed a higher score $($ mean $=53.11, \mathrm{SD}=6.33)$ than the PIGD-N group (mean $=47.73, \mathrm{SD}=7.72$ ). No other group differences were found. No significant correlations were found between neuropsychological results and UPDRS-III scores. 
medRxiv preprint doi: https://doi.org/10.1101/2020.08.15.20174284; this version posted August 17, 2020. The copyright holder for this preprint (which was not certified by peer review) is the author/funder, who has granted medRxiv a license to display the preprint in It is made available under a CC-BY-NC-ND 4.0 International license .

\section{Table 1}

Characteristics of the cohort of PD-N and two motor phenotypes.

\begin{tabular}{|c|c|c|c|c|}
\hline & $\begin{array}{l}\text { PD-N } \\
(n=34)\end{array}$ & $\begin{array}{l}\text { TD-N } \\
(n=19)\end{array}$ & $\begin{array}{l}\text { PIGD-N } \\
(n=15)\end{array}$ & $\begin{array}{l}p \text { value } \\
\text { (TD-N vs. } \\
\text { PIGD-N) }\end{array}$ \\
\hline \multicolumn{5}{|l|}{ Demographics } \\
\hline Age (years) & $57.50 \pm 7.79$ & $57.26 \pm 7.82$ & $57.80 \pm 8.03$ & 0.846 \\
\hline Gender $(\mathrm{M} / \mathrm{F})$ & $11 \mathrm{M} / 23 \mathrm{~F}$ & $5 \mathrm{M} / 14 \mathrm{~F}$ & $6 \mathrm{M} / 9 \mathrm{~F}$ & 0.701 \\
\hline Education (years) & $15.31 \pm 2.11$ & $14.89 \pm 1.94$ & $15.80 \pm 2.34$ & 0.237 \\
\hline \multicolumn{5}{|c|}{ Disease-related symptoms } \\
\hline MMSE & $29 \pm 1.7$ & $29 \pm 2.4$ & $29 \pm 0.5$ & 0.307 \\
\hline $\begin{array}{l}\text { Disease duration } \\
\text { (years) }\end{array}$ & $12.79 \pm 6.29$ & $12.53 \pm 5.63$ & $13.13 \pm 7.22$ & 0.791 \\
\hline LED (mg/day) & $901.30 \pm 509.31$ & $881.69 \pm 554.36$ & $926.80 \pm 472.28$ & 0.835 \\
\hline UPDRS III OFF & $39.71 \pm 12.64$ & $40.68 \pm 13.71$ & $38.47 \pm 11.47$ & 0.611 \\
\hline UPDRS III ON & $33.23 \pm 12.81$ & $33.57 \pm 12.21$ & $32.38 \pm 13.42$ & 0.831 \\
\hline Tremor score & $1.85 \pm 1.25$ & $2.67 \pm 1.03$ & $0.82 \pm 0.52$ & $<0.001 *$ \\
\hline Rest tremor & $0.45 \pm 0.19$ & $0.39 \pm 0.19$ & $0.53 \pm 0.16$ & $0.026 *$ \\
\hline Active tremor & $0.22 \pm 0.10$ & $0.19 \pm 0.10$ & $0.27 \pm 0.08$ & $0.014^{*}$ \\
\hline PIGD score & $1.70 \pm 0.60$ & $1.61 \pm 0.60$ & $1.89 \pm 0.54$ & 0.163 \\
\hline Rigidity score & $1.35 \pm 0.89$ & $1.14 \pm 0.85$ & $1.63 \pm 0.91$ & 0.118 \\
\hline Bradykinesia score & $2.23 \pm 0.95$ & $1.95 \pm 0.97$ & $2.67 \pm 0.82$ & $0.025^{*}$ \\
\hline DRS-II & $138.74 \pm 4.85$ & $138.58 \pm 5.14$ & $138.93 \pm 3.94$ & 0.823 \\
\hline BDI & $7.27 \pm 5.37$ & $8.63 \pm 5.97$ & $5.53 \pm 4.03$ & 0.081 \\
\hline FSIQ & $101.7 \pm 13.15$ & $104.63 \pm 14.42$ & $98.6 \pm 11.3$ & 0.181 \\
\hline
\end{tabular}

Note: * statistically significant $(p<0.05)$. MMSE $=$ the Mini-Mental State Examination. LED $=$ Levodopa dosage equivalence. UPDRS-III = Unified Parkinson's Disease Rating Scale part III. DRS-II = Dementia rating scale-II. BDI $=$ Beck Depression Inventory. FSIQ $=$ Full Scale Intelligence Quotient. The following motor scores were from items in UPDRS-III. Tremor score $=$ the sum of items 20 and 21, divided by 4 . Rest tremor score $=$ the sum of item 20 divided by 5. Active tremor score $=$ the sum of item 21 divided by 2 . PIGD 
medRxiv preprint doi: https://doi.org/10.1101/2020.08.15.20174284; this version posted August 17, 2020. The copyright holder for this preprint (which was not certified by peer review) is the author/funder, who has granted medRxiv a license to display the preprint in It is made available under a CC-BY-NC-ND 4.0 International license.

score $=$ the sum of items $22-27$ and 31, divided by 15 from. Rigidity score $=$ the sum of item 22 divided by 5. Bradykinesia score $=$ item 23 .

\section{Table 2}

Executive Function comparison across motor phenotypes.

\begin{tabular}{lllll}
\hline & PD-N & TD-N & PIGD-N & $\begin{array}{l}p \text { value } \\
\text { (TD-N } \\
\text { vs. } \\
\text { PIGD-N })\end{array}$ \\
& $(\mathrm{n}=34)$ & $(\mathrm{n}=19)$ & $(\mathrm{n}=15)$ & 0.231 \\
\hline Trail Making A & $48.06 \pm 11.02$ & $50.05 \pm 10.92$ & $45.43 \pm 10.99$ & 0.889 \\
Trail Making B & $47.85 \pm 8.67$ & $46.44 \pm 11.92$ & $45.93 \pm 9.15$ & 0.098 \\
Stroop Word Reading & $44.94 \pm 7.52$ & $43.11 \pm 8.23$ & $47.27 \pm 5.98$ & 0.073 \\
Stroop Color Naming & $41.68 \pm 8.07$ & $42.05 \pm 7.20$ & $41.2 \pm 9.29$ & 0.773 \\
Stroop Color-Word Interference & $48.91 \pm 9.02$ & $48.68 \pm 10.48$ & $49.2 \pm 7.63$ & 0.869 \\
FAS Verbal Fluency & $51.41 \pm 11.22$ & $53.11 \pm 6.33$ & $47.73 \pm 7.72$ & $0.033^{*}$ \\
Animal Verbal Fluency & $49.50 \pm 9.56$ & $48.21 \pm 7.9$ & $49.47 \pm 10.34$ & 0.699 \\
\hline
\end{tabular}

Note: * statistically significant $(p<0.05)$. Values was expressed as mean \pm standard deviation. All subtests of EF are from Delis-Kaplan Executive Function System.

\subsection{Effects of PD motor phenotypes on alterations of WM related to EF}

ANCOVA results showed significant difference between the two phenotypes in the MD and RD of the WM connecting task-based ROIs after controlling for age, disease duration, and scores of the FAS verbal fluency task $\left[\mathrm{F}_{\mathrm{RD}(1,18)}=12.62, p=0.0004\right.$. $\left.\mathrm{F}_{\mathrm{MD}(1,18)}=14.26, p=0.0002\right]$. Post-hoc $t$-tests indicated significant differences in MD and RD in the left SLF, connecting the left STG and left insula, and in the right fronto-insular fibers, anatomically connecting the pars opercularis and insula [48]. The right frontal U-fibers connecting pars opercularis and pars triangularis, and the right temporal U-fibers connecting ITG and MTG showed statistically significant differences in the post-hoc analysis of RD (described in Table 3). Phenotype $\times$ FAS scores interactions were significant for MD and RD [FR (1, 18) $\left.=4.262, p=0.039 ; \mathrm{F}_{\mathrm{MD}(1,18)}=5.20, p=0.023\right]$. Neither an interaction in phenotype $\times$ age nor in phenotype $\times$ disease duration was found.

\section{Table 3}

FAS verbal fluency network: MD and RD results. 
medRxiv preprint doi: https://doi.org/10.1101/2020.08.15.20174284; this version posted August 17, 2020. The copyright holder for this preprint (which was not certified by peer review) is the author/funder, who has granted medRxiv a license to display the preprint in It is made available under a CC-BY-NC-ND 4.0 International license .

\begin{tabular}{|c|c|c|c|c|}
\hline ROIs pair & $\begin{array}{l}\text { anatomical WM } \\
\text { fibers }\end{array}$ & TD-N & PIGD-N & $p$ value \\
\hline \multicolumn{5}{|l|}{$\operatorname{MD}\left(10^{-3} \mathrm{~mm}^{2} / \mathrm{s}\right)$} \\
\hline $\begin{array}{l}\text { lh-superior temporal gyrus } \\
\text { lh-insula }\end{array}$ & $\begin{array}{l}\text { left superior } \\
\text { longitudinal } \\
\text { fasciculi }\end{array}$ & $0.775 \pm 0.023$ & $0.758 \pm 0.040$ & 0.005 \\
\hline $\begin{array}{l}\text { rh-pars opercularis gyrus } \\
\text { rh-insula }\end{array}$ & $\begin{array}{l}\text { right fronto-insular } \\
\text { tracts }\end{array}$ & $0.740 \pm 0.022$ & $0.750 \pm 0.031$ & 0.004 \\
\hline \multicolumn{5}{|l|}{$\mathrm{RD}\left(10^{-3} \mathrm{~mm}^{2} / \mathrm{s}\right)$} \\
\hline $\begin{array}{l}\text { lh-superior temporal gyrus _ } \\
\text { lh-insula }\end{array}$ & $\begin{array}{l}\text { left superior } \\
\text { longitudinal } \\
\text { fasciculi }\end{array}$ & $0.603 \pm 0.024$ & $0.605 \pm 0.036$ & 0.005 \\
\hline $\begin{array}{l}\text { rh-inferior temporal gyrus } \\
\text { rh-middle temporal gyrus }\end{array}$ & $\begin{array}{l}\text { right temporal U- } \\
\text { fibers }\end{array}$ & $0.602 \pm 0.019$ & $0.599 \pm 0.029$ & 0.01 \\
\hline $\begin{array}{l}\text { rh-pars opercularis_rh- } \\
\text { insula }\end{array}$ & $\begin{array}{l}\text { right fronto-insular } \\
\text { tracts }\end{array}$ & $0.589 \pm 0.025$ & $0.598 \pm 0.035$ & 0.003 \\
\hline $\begin{array}{l}\text { rh-pars opercularis_rh-pars } \\
\text { triangularis }\end{array}$ & $\begin{array}{l}\text { right frontal U- } \\
\text { fibers }\end{array}$ & $0.588 \pm 0.024$ & $0.607 \pm 0.064$ & 0.01 \\
\hline
\end{tabular}

Note: values are expressed as mean \pm standard deviation. $\mathrm{rh}=$ right hemisphere. $\mathrm{lh}=$ left hemisphere. The ANCOVA was performed with subjects' age, years of disease duration, FAS verbal fluency task scores as covariates.

\subsection{Characteristics of WM integrity correlated with performance of FAS verbal fluency task in the} cohort of PD-N patients

The ANCOVA model showed significantly increased MD in tracts connecting cortico-cortical and cortico-subcortical regions in both hemispheres $\left[\mathrm{F}_{(1,31)}=4.89, p=0.027\right]$, but not significant FA or RD differences were found (detailed in Table 4).

\section{Table 4}

Effects of FAS verbal fluency scores in the whole brain network for the PD-N cohort: MD results.

ROIs pair $\operatorname{MD}\left(10^{-3} \mathrm{~mm}^{2} / \mathrm{s}\right) \quad p$ value

\section{Cortical regions}

Frontal cortex
rh-caudal middle frontal gyrus__ rh-superior frontal gyrus
$0.737 \pm 0.030$
0.011
rh-caudal middle frontal gyrus
rh-precentral cortex
$0.730 \pm 0.025$
0.015 
medRxiv preprint doi: https://doi.org/10.1101/2020.08.15.20174284; this version posted August 17, 2020. The copyright holder for this preprint (which was not certified by peer review) is the author/funder, who has granted medRxiv a license to display the preprint in It is made available under a CC-BY-NC-ND 4.0 International license .

rh-pars triangularis__ rh-rostral middle frontal gyrus

$0.757 \pm 0.053 \quad 0.034$

rh-medial orbitofrontal cortex rh-rostral anterior

cingulate cortex

$0.804 \pm 0.038 \quad 0.024$

Temporal cortex
rh-inferior temporal gyrus__ rh-insula
$0.781 \pm 0.031$
0.045
rh-inferior temporal gyrus__ rh-superior temporal gyrus
$0.768 \pm 0.026 \quad 0.036$

Parietal cortex

$\begin{array}{lll}\text { rh-superior parietal cortex__ rh-supramarginal gyrus } & 0.767 \pm 0.037 & 0.037\end{array}$

Occipital cortex

$\begin{array}{lll}\text { lh-cuneus cortex _ lh-pericalcarine cortex } & 0.780 \pm 0.040 & 0.028\end{array}$

Fronto-temporal cortex

rh-pars triangularis__rh-insula

$0.745 \pm 0.024 \quad 0.018$

rh-precentral cortex_ rh-insula

$0.742 \pm 0.030 \quad 0.012$

Fronto-parietal cortex

rh-postcentral cortex_ rh-precentral cortex

$0.753 \pm 0.030 \quad 0.023$

lh-precentral cortex _ lh-superior parietal cortex

$0.734 \pm 0.028 \quad 0.037$

Temporo-parietal cortex

rh-postcentral cortex_ rh-insula

$0.76 \pm 0.0370 \quad 0.048$

rh-supramarginal gyrus _ rh-insula

$0.756 \pm 0.031 \quad 0.042$

Parieto-occipital cortex

lh-pericalcarine cortex _ lh-precuneus cortex

$0.805 \pm 0.041 \quad 0.047$

rh-cuneus cortex_rh-precuneus cortex

$0.765 \pm 0.035 \quad 0.021$

rh-fusiform gyrus__ rh-para hippocampal gyrus

$0.832 \pm 0.115 \quad 0.049$

Cortico-subcortical regions

lh-Pallidum lh-insula cortex

$0.731 \pm 0.051$

0.044

Note: values are expressed as mean \pm standard deviation. rh: right hemisphere. lh: left hemisphere. Age, years of duration, and phenotype were defined as covariates in the ANCOVA model.

\section{Discussion}

In this study, we investigated the differences in WM integrity underlying the FAS verbal fluency network between the PIGD-N and the TD-N phenotypes, and analyzed the WM properties related to EF in PD-N patients at the whole brain level, regardless of phenotype effect. Our results showed a greater loss in WM integrity with lower EF in PIGD-N compared to TD-N phenotype, which is in 
medRxiv preprint doi: https://doi.org/10.1101/2020.08.15.20174284; this version posted August 17, 2020. The copyright holder for this preprint (which was not certified by peer review) is the author/funder, who has granted medRxiv a license to display the preprint in It is made available under a CC-BY-NC-ND 4.0 International license.

agreement with a previous study [14]. In addition, we confirmed that SLF MD and RD values are correlated with EF in PD-N patients, as previously reported [12,49-52].

\subsection{Cognitive results}

Our PIGD-N cohort had lower scores in the FAS verbal fluency task than the TD-N one, which is in agreement with a previous study [12]. Other studies reported that patients with the PIGD-N phenotype had lower scores in other cognitive tasks, such as MMSE, Montreal Cognitive Assessment, Attention, and the Trail Making Tests when compared to patients with the TD-N phenotype $[6,53,54]$, suggesting that global cognitive functions differs between the two phenotypes, even when cognition is considered normal. The neuropsychological tests included in our study are closely related with multiple neuropsychological processes of EF. The processes underlying the Trail Making A and B tests demanded high graphomotor ability [55]. The Stroop color-word interference and verbal fluency tasks demanded high working memory, association, selection and inhibition abilities [56-58]. We found no significant differences between the two phenotypes for the Trial Making Tests in our study. These suggests that tasks such as association and selection were more fragile than graphomotor abilities in the PIGD-N group, or both subgroups were equally affected.

\subsection{FAS verbal fluency network and PD motor phenotype}

The WM tract connecting STG with insula showed increased MD and RD in the PIGD-N group. The tract was anatomically matched to the SLF, an important tract for EF. Previous studies reported decreased FA in SLF and corpus callosum in PIGD compared to normal control, but no such differences were found in TD [14,49,59-62]. These previous results used different processing methods, did not account for cognitive function, and compared PIGD-N to normal controls, rather than between PD motor phenotypes. Therefore, due to methodological differences, our results are not directly comparable with those studies. However, as a collection, these studies all point towards the presence of an altered SLF in the PIGD-N group.

In addition, the WM tracts between ROI pairs, including the IFG pars opercularis gyrus and insula, pars opercularis and pars triangularis, right ITG with MTG, showed significant RD differences between the two phenotypes. The pars opercularis and insula are reportedly involved in speech articulation, vocalization of emotional states, and facial expression [48]. Especially, the WM tracts between pars opercularis and pars triangularis are involved in semantic processing, including lexis association and selection [63]. Thus, our results suggest that both facial muscle rigidity and language 
medRxiv preprint doi: https://doi.org/10.1101/2020.08.15.20174284; this version posted August 17, 2020. The copyright holder for this preprint (which was not certified by peer review) is the author/funder, who has granted medRxiv a license to display the preprint in It is made available under a CC-BY-NC-ND 4.0 International license.

processing might be altered in PIGD-N phenotype. Compared to the TD phenotype, increased MD in tracts among the right inferior parietal lobe, premotor, and primary motor cortex in PIGD phenotype were previously reported [59]. These regions were not included in our FAS verbal fluency network, and at the whole brain level we did not compare phenotypes, as we focused on the effect of FAS verbal fluency in PD-N irrespective of phenotype. Therefore, we cannot compare those findings to our results.

\subsection{Characteristics of WM integrity correlated with performance of FAS verbal fluency task in the} cohort of PD-N patients

In our cohort of PD-N patients, the WM alterations related to the FAS verbal fluency task scores were characterized by increases in MD of inter- and intra-regional connections between cortex and subcortex in both hemispheres. In the frontal cortex we observed MD changes in the short U tracts between the right caudal MFG and the SFG, and in the $\mathrm{U}$ tracts connecting the right MFG and the precentral cortex. The function of these connections are still not clear, but the three regions are connected with the striatum through descending projection fibers [48]. The connections between medial orbitofrontal cortex and anterior cingulate cortex are part of the fronto-orbitopolar tract $[64,65]$. The tracts connecting the left precentral cortex and superior parietal cortex are important in attention and spatial visual abilities [66]. Duncan et al. reported significant decreased phonemic and semantic fluency scores in PD-N compared to normal controls [19]. They reported increased MD in connections between frontal and parietal WM which correlated with deficits in semantic fluency performance in PD-N. Although we evaluated a different cognitive task, our observed alterations in tracts connecting frontal and parietal cortex are in line with their findings. It is possible that both phonemic and semantic verbal fluency tasks share basic circuits for lexis association and selection processes [67]. We reported alterations of tracts connecting right frontal and insular regions as well as the tracts connecting right frontal and striatal regions. Fronto-insular-striatal tracts are involved in attention, sensory memory, and motor speech functions, suggesting these cognitive domains are disturbed in PD-N patients $[68,69]$. We also found the SLF integrity was correlated to the EF in PD, as previous studies reported [12,4952].

We found alterations in MD, but not in FA and RD, in the cohort of PD-N patients, in agreement with previous studies $[12,19]$. This suggests that PD-N might present changes related to membrane integrity, which could be caused by cellularity, edema, or necrosis [70]. In addition, we reported the characteristic parameters related to EF in PIGD-N are the increased MD and RD, not the FA. RD changes have been associated with loss of the integrity and properties of the myelin sheath [71]. Other studies reported a significant reduction in FA in the left parietal, and prefrontal WM in non-demented 
medRxiv preprint doi: https://doi.org/10.1101/2020.08.15.20174284; this version posted August 17, 2020. The copyright holder for this preprint (which was not certified by peer review) is the author/funder, who has granted medRxiv a license to display the preprint in It is made available under a CC-BY-NC-ND 4.0 International license.

PD patients with EF impairment tested by Wisconsin card sorting test [72-74]. These studies were not restricted to PD-N, and different neuropsychological tests may result in the differences. Thus, our results suggest $\mathrm{MD}$ and $\mathrm{RD}$ values could aid detecting WM alterations related to EF in PD patients having normal cognitive functions, especially for the PIGD phenotype.

There are some limitations of this study. We acknowledge a small sample set per subgroup, limiting our results. We compared cognitive scores using a cross-sectional design, longitudinal studies could shed more light into the WM integrity changes and their relationship with behavior. Tractography is not a perfect tool for mapping WM pathways, resulting in both false "negatives" and "positives" in its connection maps; however, it provides a methodology for parcellating the WM skeleton relatively consistently across a group, using each subject's own data. Considering the motor phenotype can shift from TD to PIGD phenotype, the repeated prospective measurements in a longitudinal design might be of interest. Finally, we did not examined the medication effect on behavior.

\section{Conclusion}

The present study reinforces the concept of overt clinical cognitive deficits present in PD-N. PIGD-N shows more microstructural changes related to when compared to TD-N phenotype. The mechanisms of phenotype effects on WM integrity alterations related to cognitive functions can be comprehensively studied in longitudinal studies in the future.

\section{Declaration of Interests}

The authors declare no competing interests.

\section{Acknowledgments and Funding}

This work was supported by the NINDS Intramural Research Program; and the National Institutes of Health Graduate Partnerships Program. QY stipends in NIH was supported by the Joint-Ph.D. program of the China Scholarship Council. PAT was supported by the NIMH and NINDS Intramural Research Programs (ZICMH002888) of the NIH (HHS, USA). We sincerely thank Dr. Gang Chen for his advice on statistics.

\section{Reference}


medRxiv preprint doi: https://doi.org/10.1101/2020.08.15.20174284; this version posted August 17, 2020. The copyright holder for this preprint (which was not certified by peer review) is the author/funder, who has granted medRxiv a license to display the preprint in

It is made available under a CC-BY-NC-ND 4.0 International license .

[1] O.-B. Tysnes, A. Storstein, Epidemiology of Parkinson's disease., J. Neural Transm. 124 (2017) 901-905. https://doi.org/10.1007/s00702-017-1686-y.

[2] J. Jankovic, Parkinson's disease: Clinical features and diagnosis, J. Neurol. Neurosurg. Psychiatry. (2008). https://doi.org/10.1136/jnnp.2007.131045.

[3] M.C. Rodriguez-Oroz, M. Jahanshahi, P. Krack, I. Litvan, R. Macias, E. Bezard, J.A. Obeso, Initial clinical manifestations of Parkinson's disease: features and pathophysiological mechanisms, Lancet Neurol. 8 (2009) 1128-1139.

https://doi.org/https://doi.org/10.1016/S1474-4422(09)70293-5.

[4] J. Jankovic, M. McDermott, J. Carter, S. Gauthier, C. Goetz, L. Golbe, S. Huber, W. Koller, C. Olanow, I. Shoulson, et al., Variable expression of Parkinson's disease: a base-line analysis of the DATATOP cohort. The Parkinson Study Group, Neurology. 40 (1990) 1529-1534. https://doi.org/10.1212/wnl.40.10.1529.

[5] Y. Yang, B.S. Tang, J.F. Guo, Parkinson's Disease and Cognitive Impairment, Park. Dis. 2016 (2016) 6734678. https://doi.org/10.1155/2016/6734678.

[6] J.G. Goldman, B.A. Vernaleo, R. Camicioli, N. Dahodwala, R.D. Dobkin, T. Ellis, J.E. Galvin, C. Marras, J. Edwards, J. Fields, R. Golden, J. Karlawish, B. Levin, L. Shulman, G. Smith, C. Tangney, C.A. Thomas, A.I. Troster, E.Y. Uc, N. Coyan, C. Ellman, M. Ellman, C. Hoffman, S. Hoffman, D. Simmonds, Cognitive impairment in Parkinson's disease: a report from a multidisciplinary symposium on unmet needs and future directions to maintain cognitive health, NPJ Park. Dis. 4 (2018) 19. https://doi.org/10.1038/s41531-018-0055-3.

[7] D. Aarsland, B. Creese, M. Politis, K.R. Chaudhuri, D.H. Ffytche, D. Weintraub, C. Ballard, Cognitive decline in Parkinson disease, Nat Rev Neurol. 13 (2017) 217-231. https://doi.org/10.1038/nrneurol.2017.27.

[8] G. Alves, J.P. Larsen, M. Emre, T. Wentzel-Larsen, D. Aarsland, Changes in motor subtype and risk for incident dementia in Parkinson's disease, Mov Disord. 21 (2006) 1123-1130. https://doi.org/10.1002/mds.20897.

[9] J. Pagonabarraga, J. Kulisevsky, Cognitive impairment and dementia in Parkinson's disease, Neurobiol Dis. 46 (2012) 590-596. https://doi.org/10.1016/j.nbd.2012.03.029.

[10] D. Aarsland, K. Andersen, J.P. Larsen, A. Lolk, P. Kragh-Sorensen, Prevalence and characteristics of dementia in Parkinson disease: an 8-year prospective study, Arch Neurol. 60 (2003) 387-392. https://doi.org/10.1001/archneur.60.3.387.

[11] D.J. Burn, E.N. Rowan, L.M. Allan, S. Molloy, J.T. O’Brien, I.G. McKeith, Motor subtype and cognitive decline in Parkinson's disease, Parkinson's disease with dementia, and dementia with Lewy bodies, J Neurol Neurosurg Psychiatry. 77 (2006) 585-589. https://doi.org/10.1136/jnnp.2005.081711.

[12] T.R. Melzer, R. Watts, M.R. MacAskill, T.L. Pitcher, L. Livingston, R.J. Keenan, J.C. Dalrymple-Alford, T.J. Anderson, White matter microstructure deteriorates across cognitive stages in Parkinson disease, Neurology. 80 (2013) 1841-1849. https://doi.org/10.1212/WNL.0b013e3182929f62.

[13] Z. Zheng, S. Shemmassian, C. Wijekoon, W. Kim, S.Y. Bookheimer, N. Pouratian, DTI correlates of distinct cognitive impairments in Parkinson's disease, Hum Brain Mapp. 35 (2014) 1325-1333. https://doi.org/10.1002/hbm.22256.

[14] G. Vervoort, I. Leunissen, M. Firbank, E. Heremans, E. Nackaerts, W. Vandenberghe, A. Nieuwboer, Structural Brain Alterations in Motor Subtypes of Parkinson's Disease: Evidence from Probabilistic Tractography and Shape Analysis, PLoS One. 11 (2016) e0157743. https://doi.org/10.1371/journal.pone.0157743.

[15] A.L. Alexander, J.E. Lee, M. Lazar, A.S. Field, Diffusion tensor imaging of the brain, Neurotherapeutics. 4 (2007) 316-329. https://doi.org/10.1016/j.nurt.2007.05.011.

[16] P.J. Basser, J. Mattiello, D. LeBihan, MR diffusion tensor spectroscopy and imaging, Biophys J. 66 (1994) 259-267. https://doi.org/10.1016/S0006-3495(94)80775-1. 
medRxiv preprint doi: https://doi.org/10.1101/2020.08.15.20174284; this version posted August 17, 2020. The copyright holder for this preprint (which was not certified by peer review) is the author/funder, who has granted medRxiv a license to display the preprint in

It is made available under a CC-BY-NC-ND 4.0 International license .

[17] P. Mukherjee, J.I. Berman, S.W. Chung, C.P. Hess, R.G. Henry, Diffusion tensor MR imaging and fiber tractography: theoretic underpinnings, AJNR Am J Neuroradiol. 29 (2008) 632-641. https://doi.org/10.3174/ajnr.A1051.

[18] S.R. Cox, S.J. Ritchie, E.M. Tucker-Drob, D.C. Liewald, S.P. Hagenaars, G. Davies, J.M. Wardlaw, C.R. Gale, M.E. Bastin, I.J. Deary, Ageing and brain white matter structure in 3,513 UK Biobank participants, Nat Commun. 7 (2016) 13629.

https://doi.org/10.1038/ncomms 13629.

[19] G.W. Duncan, M.J. Firbank, A.J. Yarnall, T.K. Khoo, D.J. Brooks, R.A. Barker, D.J. Burn, J.T. O'Brien, Gray and white matter imaging: A biomarker for cognitive impairment in early Parkinson's disease?, Mov Disord. 31 (2016) 103-110. https://doi.org/10.1002/mds.26312.

[20] A.J. Hughes, S.E. Daniel, L. Kilford, A.J. Lees, Accuracy of clinical diagnosis of idiopathic Parkinson's disease: A clinico-pathological study of 100 cases, J. Neurol. Neurosurg. Psychiatry. 55 (1992) 181-184. https://doi.org/10.1136/jnnp.55.3.181.

[21] A.J. Hughes, Y. Ben-Shlomo, S.E. Daniel, A.J. Lees, What features improve the accuracy of clinical diagnosis in Parkinson's disease: a clinicopathologic study. 1992, Neurology. 57 (2001) S34-8.

[22] S.M. Brucki, R. Nitrini, P. Caramelli, P.H. Bertolucci, I.H. Okamoto, Suggestions for utilization of the mini-mental state examination in Brazil, Arq Neuropsiquiatr. 61 (2003) 777 781. https://doi.org/10.1590/s0004-282x2003000500014.

[23] C.C. Goetz, The Unified Parkinson's Disease Rating Scale (UPDRS): Status and recommendations, Mov. Disord. 18 (2003) 738-750. https://doi.org/10.1002/mds.10473.

[24] M.M. Hoehn, M.D. Yahr, Parkinsonism: onset, progression and mortality, Neurology. 17 (1967) 427-442. https://doi.org/10.1212/wnl.17.5.427.

[25] C.L. Tomlinson, R. Stowe, S. Patel, C. Rick, R. Gray, C.E. Clarke, Systematic review of levodopa dose equivalency reporting in Parkinson's disease, Mov. Disord. 25 (2010) 26492653. https://doi.org/10.1002/mds.23429.

[26] G.A. Kang, J.M. Bronstein, D.L. Masterman, M. Redelings, J.A. Crum, B. Ritz, Clinical characteristics in early Parkinson's disease in a central California population-based study, Mov Disord. 20 (2005) 1133-1142. https://doi.org/10.1002/mds.20513.

[27] A. Korchounov, H.I. Schipper, I.S. Preobrazhenskaya, K.R. Kessler, N.N. Yakhno, Differences in age at onset and familial aggregation between clinical types of idiopathic Parkinson's disease, Mov Disord. 19 (2004) 1059-1064. https://doi.org/10.1002/mds.20061.

[28] D.C. Delis, J.H. Kramer, E. Kaplan, J. Holdnack, Reliability and validity of the Delis-Kaplan Executive Function System: an update, J Int Neuropsychol Soc. 10 (2004) 301-303. https://doi.org/10.1017/S1355617704102191.

[29] D.C. Delis, E. Kaplan, J.H. Kramer, Delis-Kaplan executive function system: Examiner's manual. San Antonio, TX: The Psychological Corporation. , (2001).

[30] P.M. Lauro, N. Vanegas-Arroyave, L. Huang, P.A. Taylor, K.A. Zaghloul, C. Lungu, Z.S. Saad, S.G. Horovitz, DBSproc: An open source process for DBS electrode localization and tractographic analysis, Hum Brain Mapp. 37 (2016) 422-433. https://doi.org/10.1002/hbm.23039.

[31] P.L. Bazin, J.L. Cuzzocreo, M.A. Yassa, W. Gandler, M.J. McAuliffe, S.S. Bassett, D.L. Pham, Volumetric neuroimage analysis extensions for the MIPAV software package, J Neurosci Methods. 165 (2007) 111-121. https://doi.org/10.1016/j.jneumeth.2007.05.024.

[32] P.A. Taylor, K.H. Cho, C.P. Lin, B.B. Biswal, Improving DTI tractography by including diagonal tract propagation, PLoS One. 7 (2012) e43415. https://doi.org/10.1371/journal.pone.0043415.

[33] B. Fischl, FreeSurfer, Neuroimage. 62 (2012) 774-781. https://doi.org/10.1016/j.neuroimage.2012.01.021.

[34] R.W. Cox, AFNI: software for analysis and visualization of functional magnetic resonance 
medRxiv preprint doi: https://doi.org/10.1101/2020.08.15.20174284; this version posted August 17, 2020. The copyright holder for this preprint (which was not certified by peer review) is the author/funder, who has granted medRxiv a license to display the preprint in It is made available under a CC-BY-NC-ND 4.0 International license .

neuroimages, Comput Biomed Res. 29 (1996) 162-173.

[35] Z.S. Saad, R. R.C, B. Argall., S. Japee., C.R. .W, SUMA: An Interface For Surface-Based Intra- And Inter-Subject Analysis With AFNI, 2004 IEEE Int. Symp. Biomed. Imaging From Nano to Macro. IEEE, Arlington, VA. (2004) 1510-1513.

[36] P.A. Taylor, Z.S. Saad, FATCAT: (an efficient) Functional and Tractographic Connectivity Analysis Toolbox, Brain Connect. 3 (2013) 523-535. https://doi.org/10.1089/brain.2013.0154.

[37] R.S. Desikan, F. Segonne, B. Fischl, B.T. Quinn, B.C. Dickerson, D. Blacker, R.L. Buckner, A.M. Dale, R.P. Maguire, B.T. Hyman, M.S. Albert, R.J. Killiany, An automated labeling system for subdividing the human cerebral cortex on MRI scans into gyral based regions of interest, Neuroimage. 31 (2006) 968-980. https://doi.org/10.1016/j.neuroimage.2006.01.021.

[38] E.M. Weiss, A. Hofer, S. Golaszewski, C. Siedentopf, C. Brinkhoff, C. Kremser, S. Felber, W.W. Fleischhacker, Brain activation patterns during a verbal fluency test-a functional MRI study in healthy volunteers and patients with schizophrenia, Schizophr Res. 70 (2004) 287291. https://doi.org/10.1016/j.schres.2004.01.010.

[39] R. Schlosser, M. Hutchinson, S. Joseffer, H. Rusinek, A. Saarimaki, J. Stevenson, S.L. Dewey, J.D. Brodie, Functional magnetic resonance imaging of human brain activity in a verbal fluency task, J Neurol Neurosurg Psychiatry. 64 (1998) 492-498. https://doi.org/10.1136/jnnp.64.4.492.

[40] R. Cox, D. Glen, Nonlinear warping in afni, Poster Present. 19th Annu. Meet. 514 Organ. Hum. Brain Mapp. (2013).

[41] B. Deng, Y. Zhang, L. Wang, K. Peng, L. Han, K. Nie, H. Yang, L. Zhang, J. Wang, Diffusion tensor imaging reveals white matter changes associated with cognitive status in patients with Parkinson's disease, Am J Alzheimers Dis Other Demen. 28 (2013) 154-164. https://doi.org/10.1177/1533317512470207.

[42] S. Vercruysse, M. Gilat, J.M. Shine, E. Heremans, S. Lewis, A. Nieuwboer, Freezing beyond gait in Parkinson's disease: a review of current neurobehavioral evidence, Neurosci Biobehav Rev. 43 (2014) 213-227. https://doi.org/10.1016/j.neubiorev.2014.04.010.

[43] L.L. Chan, K.M. Ng, H. Rumpel, S. Fook-Chong, H.H. Li, E.K. Tan, Transcallosal diffusion tensor abnormalities in predominant gait disorder parkinsonism, Park. Relat Disord. 20 (2014) 53-59. https://doi.org/10.1016/j.parkreldis.2013.09.017.

[44] Z.S. Saad, D.R. Glen, G. Chen, M.S. Beauchamp, R. Desai, R.W. Cox, A new method for improving functional-to-structural MRI alignment using local Pearson correlation, NeuroImage . 44 (2009) 839-848.

[45] P.A. Taylor, G. Chen, R.W. Cox, Z.S. Saad, Open Environment for Multimodal Interactive Connectivity Visualization and Analysis, Brain Connect. 6 (2016) 109-121. https://doi.org/10.1089/brain.2015.0363.

[46] G. Chen, N.E. Adleman, Z.S. Saad, E. Leibenluft, R.W. Cox, Applications of multivariate modeling to neuroimaging group analysis: A comprehensive alternative to univariate general linear model, Neuroimage. 99 (2014) 571-588.

https://doi.org/10.1016/j.neuroimage.2014.06.027.

[47] G. Chen, Z.S. Saad, N.E. Adleman, E. Leibenluft, R.W. Cox, Detecting the subtle shape differences in hemodynamic responses at the group level, Front Neurosci. 9 (2015) 375. https://doi.org/10.3389/fnins.2015.00375.

[48] M. Catani, F. Dell'acqua, F. Vergani, F. Malik, H. Hodge, P. Roy, R. Valabregue, M. Thiebaut de Schotten, Short frontal lobe connections of the human brain, Cortex. 48 (2012) 273-291. https://doi.org/10.1016/j.cortex.2011.12.001.

[49] A. Kamali, A.E. Flanders, J. Brody, J. V Hunter, K.M. Hasan, Tracing superior longitudinal fasciculus connectivity in the human brain using high resolution diffusion tensor tractography, Brain Struct Funct. 219 (2014) 269-281. https://doi.org/10.1007/s00429-012-0498-y.

[50] S.J. Forkel, S. Mahmood, F. Vergani, M. Catani, The white matter of the human cerebrum: 
medRxiv preprint doi: https://doi.org/10.1101/2020.08.15.20174284; this version posted August 17, 2020. The copyright holder for this preprint (which was not certified by peer review) is the author/funder, who has granted medRxiv a license to display the preprint in It is made available under a CC-BY-NC-ND 4.0 International license .

part I The occipital lobe by Heinrich Sachs, Cortex. 62 (2015) 182-202. https://doi.org/10.1016/j.cortex.2014.10.023.

[51] C.Y. Lee, H.L. Chen, P.C. Chen, Y.S. Chen, P.L. Chiang, C.K. Wang, C.H. Lu, M.H. Chen, K.H. Chou, Y.C. Huang, W.C. Lin, Correlation between Executive Network Integrity and Sarcopenia in Patients with Parkinson's Disease, Int J Env. Res Public Heal. 16 (2019) 4884. https://doi.org/10.3390/ijerph16244884.

[52] P. Linortner, C. McDaniel, M. Shahid, T.F. Levine, L. Tian, B. Cholerton, K.L. Poston, White Matter Hyperintensities Related to Parkinson's Disease Executive Function, Mov. Disord. Clin. Pract. (2020) 1-10. https://doi.org/10.1002/mdc3.12956.

[53] J.Y. Oh, Y.S. Kim, B.H. Choi, E.H. Sohn, A.Y. Lee, Relationship between clinical phenotypes and cognitive impairment in Parkinson's disease (PD), Arch Gerontol Geriatr. 49 (2009) 351354. https://doi.org/10.1016/j.archger.2008.11.013.

[54] J. Wojtala, I.A. Heber, P. Neuser, J. Heller, E. Kalbe, S.P. Rehberg, A. Storch, K. Linse, C. Schneider, S. Gräber, D. Berg, J. Dams, M. Balzer-Geldsetzer, R. Hilker-Roggendorf, C. Oberschmidt, S. Baudrexel, K. Witt, N. Schmidt, G. Deuschl, B. Mollenhauer, C. Trenkwalder, I. Liepelt-Scarfone, A. Spottke, S. Roeske, U. Wüllner, H.U. Wittchen, O. Riedel, R. Dodel, J.B. Schulz, K. Reetz, Cognitive decline in Parkinson's disease: the impact of the motor phenotype on cognition, J Neurol Neurosurg Psychiatry. 90 (2019) 171-179. https://doi.org/10.1136/jnnp-2018-319008.

[55] A.F. Barbosa, M.C. Voos, J. Chen, D.C.V. Francato, C. de O. Souza, E.R. Barbosa, H.F. Chien, L.L. Mansur, Cognitive or Cognitive-Motor Executive Function Tasks? Evaluating Verbal Fluency Measures in People with Parkinson's Disease, Biomed Res. Int. 2017 (2017) 7893975. https://doi.org/10.1155/2017/7893975.

[56] F. Scarpina, S. Tagini, The Stroop Color and Word Test, Front. Psychol. 8 (2017) 557. https://doi.org/10.3389/fpsyg.2017.00557.

[57] T.N. Tombaugh, J. Kozak, L. Rees, Normative data stratified by age and education for two measures of verbal fluency: FAS and animal naming, Arch Clin Neuropsychol. 14 (1999) 167-177. https://www.ncbi.nlm.nih.gov/pubmed/14590600.

[58] L.N. Williams, P. Seignourel, G.P. Crucian, M.S. Okun, R.L. Rodriguez, F.M. Skidmore, P.S. Foster, C.E. th Jacobson, J. Romrell, D. Bowers, H.H. Fernandez, Laterality, region, and type of motor dysfunction correlate with cognitive impairment in Parkinson's disease, Mov Disord. 22 (2007) 141-145. https://doi.org/10.1002/mds.21220.

[59] G. Vervoort, K. Alaerts, A. Bengevoord, E. Nackaerts, E. Heremans, W. Vandenberghe, A. Nieuwboer, Functional connectivity alterations in the motor and fronto-parietal network relate to behavioral heterogeneity in Parkinson's disease, Park. Relat Disord. 24 (2016) 48-55. https://doi.org/10.1016/j.parkreldis.2016.01.016.

[60] N. Makris, D.N. Kennedy, S. McInerney, A.G. Sorensen, R. Wang, V.S. Caviness Jr., D.N. Pandya, Segmentation of subcomponents within the superior longitudinal fascicle in humans: a quantitative, in vivo, DT-MRI study, Cereb Cortex. 15 (2005) 854-869. https://doi.org/10.1093/cercor/bhh186.

[61] J. Ghaziri, A. Tucholka, G. Girard, J.C. Houde, O. Boucher, G. Gilbert, M. Descoteaux, S. Lippe, P. Rainville, D.K. Nguyen, The Corticocortical Structural Connectivity of the Human Insula, Cereb Cortex. 27 (2017) 1216-1228. https://doi.org/10.1093/cercor/bhv308.

[62] Q. Gu, P. Huang, M. Xuan, X. Xu, D. Li, J. Sun, H. Yu, C. Wang, W. Luo, M. Zhang, Greater loss of white matter integrity in postural instability and gait difficulty subtype of Parkinson's disease, Can J Neurol Sci. 41 (2014) 763-768. https://doi.org/10.1017/cjn.2014.34.

[63] A.D. Friederici, Chapter 10 - White-matter pathways for speech and language processing, in: M.J. Aminoff, F. Boller, D.F. Swaab (Eds.), Handb. Clin. Neurol., Elsevier, 2015: pp. 177186. https://doi.org/https://doi.org/10.1016/B978-0-444-62630-1.00010-X.

[64] K. Spyridon, V.K. Aristotelis, P.S. Georgios, D. Evangelos, L. Evgenia, L. Evangelia, L. 
medRxiv preprint doi: https://doi.org/10.1101/2020.08.15.20174284; this version posted August 17, 2020. The copyright holder for this preprint (which was not certified by peer review) is the author/funder, who has granted medRxiv a license to display the preprint in It is made available under a CC-BY-NC-ND 4.0 International license .

Faidon, K. Theodosis, P. Maria, A.E. John, S. George, K. Christos, The frontal longitudinal system as revealed through the fiber microdissection technique: structural evidence underpinning the direct connectivity of the prefrontal-premotor circuitry, J. Neurosurg. JNS. (2019) 1-13. https://doi.org/10.3171/2019.6.JNS191224.

[65] J.M. Hall, K.A. Ehgoetz Martens, C.C. Walton, C. O’Callaghan, P.E. Keller, S.J. Lewis, A.A. Moustafa, Diffusion alterations associated with Parkinson's disease symptomatology: A review of the literature, Park. Relat Disord. 33 (2016) 12-26. https://doi.org/10.1016/j.parkreldis.2016.09.026.

[66] M. Mishkin, L.G. Ungerleider, K.A. Macko, Object vision and spatial vision: two cortical pathways, Trends Neurosci. 6 (1983) 414-417. https://doi.org/https://doi.org/10.1016/01662236(83)90190-X.

[67] Z. Shao, E. Janse, K. Visser, A.S. Meyer, What do verbal fluency tasks measure? Predictors of verbal fluency performance in older adults, Front. Psychol. 5 (2014) 772. https://doi.org/10.3389/fpsyg.2014.00772.

[68] M.L. Mandelli, P. Vitali, M. Santos, M. Henry, K. Gola, L. Rosenberg, N. Dronkers, B. Miller, W.W. Seeley, M.L. Gorno-Tempini, Two insular regions are differentially involved in behavioral variant FTD and nonfluent/agrammatic variant PPA, Cortex. 74 (2016) 149-157. https://doi.org/10.1016/j.cortex.2015.10.012.

[69] C.M. Muller, R.A. de Vos, C.A. Maurage, D.R. Thal, M. Tolnay, H. Braak, Staging of sporadic Parkinson disease-related alpha-synuclein pathology: inter- and intra-rater reliability, J Neuropathol Exp Neurol. 64 (2005) 623-628. https://doi.org/10.1097/01.jnen.0000171652.40083.15.

[70] D.J. Madden, I.J. Bennett, A.W. Song, Cerebral white matter integrity and cognitive aging: contributions from diffusion tensor imaging, Neuropsychol Rev. 19 (2009) 415-435. https://doi.org/10.1007/s11065-009-9113-2.

[71] S.K. Song, S.W. Sun, M.J. Ramsbottom, C. Chang, J. Russell, A.H. Cross, Dysmyelination revealed through MRI as increased radial (but unchanged axial) diffusion of water, Neuroimage. 17 (2002) 1429-1436. https://doi.org/10.1006/nimg.2002.1267.

[72] C.L. Rae, M.M. Correia, E. Altena, L.E. Hughes, R.A. Barker, J.B. Rowe, White matter pathology in Parkinson's disease: the effect of imaging protocol differences and relevance to executive function, Neuroimage. 62 (2012) 1675-1684. https://doi.org/10.1016/j.neuroimage.2012.06.012.

[73] H. Matsui, K. Nishinaka, M. Oda, H. Niikawa, K. Komatsu, T. Kubori, F. Udaka, Wisconsin Card Sorting Test in Parkinson's disease: diffusion tensor imaging, Acta Neurol Scand. 116 (2007) 108-112. https://doi.org/10.1111/j.1600-0404.2006.00795.x.

[74] C. Atkinson-Clement, S. Pinto, A. Eusebio, O. Coulon, Diffusion tensor imaging in Parkinson's disease: Review and meta-analysis, Neuroimage Clin. 16 (2017) 98-110. https://doi.org/10.1016/j.nicl.2017.07.011. 